\title{
Economic evaluation of nurse practitioners versus GPs in treating common conditions
}

\author{
Angelique TM Dierick-van Daele, Lotte MG Steuten, Job FM Metsemakers, \\ Emmy WCC Derckx, Cor Spreeuwenberg and Hubertus JM Vrijhoef
}

\begin{abstract}
Background

As studies evaluating substitution of care have revealed only limited evidence on cost-effectiveness, a trial was conducted to evaluate nurse practitioners as a first point of contact in Dutch general practices.

Aim

To estimate costs of GP versus nurse practitioner consultations from practice and societal perspectives.

Design of study

An economic evaluation was conducted alongside a randomised controlled trial between May and October 2006, wherein 12 nurse practitioners and 50 GPs working in 15 general practices (study practices) participated. Consultations by study practices were also compared with an external reference group, with 17 GPs working in five general practices without the involvement of nurse practitioners.
\end{abstract}

\section{Method}

Direct costs within the healthcare sector included resource use, follow-up consultations, length of consultations, and salary costs. Costs outside the healthcare sector were productivity losses. Sensitivity analyses were performed.

Results

Direct costs were lower for nurse practitioner consultations than for GP consultations at study practices. This was also the case for direct costs plus costs from a societal perspective for patients aged $<65$ years. Direct costs of consultations at study practices were lower than those of reference practices, while practices did not differ for direct costs plus costs from a societal perspective for patients aged $<65$ years. Cost differences are mainly caused by the differences in salary.

\section{Conclusion}

By involving nurse practitioners, substantial economic 'savings' could be used for redesigning primary care, to optimise the best skill mix, and to cover the full range of primary care activities.

\section{Keywords}

general practitioner; cost analysis; nurse practitioner; randomised controlled trial.

\section{INTRODUCTION}

Against a background of scarce healthcare budgets, skill mix changes are being introduced to ensure health services are used efficiently. Substitution of care results in at least equivalent quality of care compared to usual care. ${ }^{1-5}$ At the same time, studies that evaluated a 'new type' of healthcare worker in terms of costs and consequences, have revealed only limited evidence on cost-effectiveness, while methodological limitations have been stressed regarding the validity and generalisability of these studies. ${ }^{5,6}$

One of these new roles is the nurse practitioner. Recent interest in substituting nurse practitioners for GPs may be driven by a goal to reduce costs while achieving similar outcomes. ${ }^{7-9}$ Given the limited number of similar studies and the concerns about their generalisability, there is also a need to perform

ATM Dierick-van Daele, MSc, research fellow, Department of Integrated Care; LMG Steuten, PhD, associate professor, Department of Health Organization, Policy and Economics; C Spreeuwenberg, $M D, P h D$, professor of integrated chronic care; JFM Metsemakers, $M D, P h D$, professor of general practice; C Spreeuwenberg, $M D, P h D$, professor of integrated chronic care; HJM Vrijhoef, PhD, associate professor, Department of Health Care \& Nursing Sciences, CAPHRI (School of Primary Care and Public Health), Maastricht University Medical Centre, Maastricht; EWCC Derckx MSc, project leader NPG study and director of the Foundation for Development of Quality Care in General Practice, Eindhoven, the Netherlands.

Address for correspondence

Mrs Angelique Theo Maria Dierick-van Daele, MUMC Maastricht University Medical Centre, Integrated Care, Postbus 5800, 6202 AZ Maastricht, Netherlands. E-mail: angeliquedierick@orange.nl

Submitted: 6 January 2009; Editor's response: 13 February 2009; final acceptance: 17 September 2009.

(C)British Journal of General Practice

This is the full-length article of an abridged version published in print. Cite this article as: Br J Gen Pract 2010; DOI: 10.3399/bjgp10X482077. 
research in Dutch general practices. It was recently demonstrated, in a randomised controlled trial (RCT,) that nurse practitioner consultations for patients with common conditions result in the same high patient satisfaction and high-quality care as GP consultations. $^{10}$

In the current paper, the authors report on healthcare utilisation and healthcare costs when patients are treated for common conditions by specially trained nurse practitioners. This study aims to estimate the costs of GP versus nurse practitioner consultations dealing with patients with common conditions from two viewpoints: general practice and societal perspectives. Provided there was equivalence in quality of care, a cost-minimisation analysis was regarded as suitable for this purpose.

\section{METHOD}

\section{Trial design}

An economic evaluation was conducted alongside an RCT between May and October 2006, wherein a convenience sample of 12 nurse practitioners and 50 GPs working in 15 general practices participated and are referred to as 'study practices'. Patients of study practices were also compared with those in an external reference group, who received treatment from one of 17 GPs working in five general practices without the involvement of a nurse practitioner.

\section{How this fits in}

Studies evaluating substitution of care have revealed only limited evidence on

cost-effectiveness. This study indicates that from practice and societal

perspectives, nurse practitioner consultations cost significantly less than GP

consultations at study practices. Direct costs of consultations at study practices

were significantly less than those of consultations in external reference

practices, while no significant differences in costs from a societal perspective

were found between these two types of practices. When involving nurse

practitioners in the care of patients with common conditions, substantial

economic savings could be used for redesigning primary care.

Comparisons were made between study practices and external reference practices, and between nurse practitioner consultations and GP consultations at study practices. The general practices range in size from solo practices (one GP) to health centres (five GPs). General practices in the external reference group range from duo practices (two GPs) to group practices (four GPs). Details about the design are described in Appendix $1 .{ }^{10} \mathrm{~A}$ description of the nurse practitioner role is further described in Box 1 .

\section{Participant recruitment}

A specified set of common conditions for which patients seek medical attention, with related

\section{Box 1. Nurse practitioner job description.}

\section{General definition of a nurse practitioner}

'A registered nurse with additional education and training, who works within an expanded scope of practice that includes diagnosing, prescribing, and treating medical conditions within specific settings. ${ }^{28}$

\section{Nurse practitioners in the Dutch project}

Target population: patients with common conditions

A specified set of common conditions was compiled for which patients seek medical attention. These common conditions will often lead to minor health problems. Patients had respiratory and throat symptoms, ear and nose symptoms, musculoskeletal symptoms and injuries, skin injuries, urinary symptoms, gynaecological symptoms, or problems related to older age.

Tasks performed

Based on triage by the practice assistant, patients with common conditions are referred to the nurse practitioner. The nurse practitioner works independently during consultations and home visits. The activities undertaken, according to practice guidelines derived by the Dutch College of General Practitioners, ${ }^{12}$ are symptom assessment, physical examinations where appropriate, diagnosing and making decisions for further treatment, prescriptions, referrals to primary or secondary services, and clinical investigations. The nurse practitioner has no full authority to prescribe medications; the GP is always available for consultation and to assign prescriptions. The nurse practitioner has access to the electronic medical records and reported consultations.

Training

Before starting a nurse practitioner training programme, the nurse practitioners has an average of 12 years' work experience (standard deviation $=7.6$ years). A specific 2 -year practice-oriented training programme has been developed, which consists of the Higher Professional Education Master's Degree Advanced Nursing Practice, and also includes a medical course on managing common conditions. During the training programme, the nurse practitioner is supervised by a GP. 
Table 1. Price-indexed unit costs (in $€$ ) in 2006.

\begin{tabular}{|c|c|c|c|}
\hline Resource use & Unit & Cost $(€)$ & Reference \\
\hline Prescriptions & Consultation & Variable & Dutch Pharmacotherapeutic Compass ${ }^{15}$ \\
\hline Referrals $^{a}$ & Consultation & Variable & Dutch Manual for Costing ${ }^{14}$ \\
\hline Diagnostic procedures & Consultation & Variable & National tariffs $2006^{24}$ \\
\hline Salary costs nurse practitioner & Year & 41160.00 & Collective labour agreement general practices \\
\hline Salary costs GP & Year & 94475.92 & Standard income ${ }^{24}$ \\
\hline Follow-up costs nurse practitioner ${ }^{b}$ & Consultation & 2.12 & Randomised controlled trial ${ }^{10}$ \\
\hline Follow-up costs GPb & Consultation & 1.65 & Randomised controlled trial ${ }^{6}$ \\
\hline Indirect costs for paid work ${ }^{c}$ & Consultation & Variable & Dutch Manual for Costing $^{14}$ \\
\hline
\end{tabular}

${ }^{a}$ Based on one initial consultation. ${ }^{b}$ Based on costs of one consultation: $€ 9.00$ and percentage of follow-up consultations (nurse practitioner: $€ 9.00 \times 23.5 \%=€ 2.12 ; G P: € 9.00 \times 18.3=€ 1.65)$. Indirect costs for paid work are based on mean income of Dutch population according to age and sex.

International Classification of Primary Care (ICPC) diagnoses, was compiled. ${ }^{11-13}$ Patients aged $>16$ years, who attended in general practice for an appointment and were visiting for an initial consultation related to common conditions were included. Patients were randomly allocated to a nurse practitioner consultation or GP consultation. In the external reference group, data were retrospectively gathered from patients with common conditions.

\section{Data collection}

Demographic characteristics and data of diagnoses (ICPC codes), prescriptions, referrals, and investigations were extracted from the health information systems of the general practices. ICPC codes were classified as low complex (code $<70$ ) or high complex (code $\geq 70$ ). Special attention was paid to ensuring the reliability of documentation by professionals. In each practice, information was given about the relevance of systematically keeping records and registering data. Software was developed to extract data from the computer systems. Extracted data were used during meetings with GPs at each general practice to provide feedback, and for testing the reliability of their documentation.

For pragmatic reasons, data for follow-up consultations, length of consultations, and number of days of absence were only gathered in study practices. It was assumed that these data were the same for the external reference group.

\section{Valuation of resource use}

All costs related to the consultations were split into costs that occurred within the healthcare sector and those that occurred outside. Direct costs within the healthcare sector included costs of prescriptions, diagnostic procedures, and referrals that were ordered in the 2 weeks after the initial consultations, follow-up consultations, length of consultations, ${ }^{10}$ and salary costs.

The cost of one initial consultation for each referral was calculated. Costs of follow-up consultations were based on percentages of patients who consulted a nurse practitioner or a GP, and had a follow-up consultation in the following 2 weeks (Table 1). ${ }^{10}$

The costs of clinical time were valued as salary plus superannuation and national insurance expenses. ${ }^{14}$ Costs of GP time were calculated at $€ 47.72$ per hour, and costs of nurse practitioner time at $€ 25.43$ per hour. The direct healthcare costs were calculated using current prices, if available, or tariffs. $^{15}$

Costs outside the healthcare sector were productivity losses, measured in terms of sick leave days and calculated using the age-dependent friction cost method..$^{14}$

To derive unit costs for the year 2006, the price index of Statistics Netherlands was used. ${ }^{16}$ Table 1 shows the key unit standardised costs per type of resource and by its reference.

\section{Analyses}

Mean costs were calculated for each group, treating each cost separately and then adding up the total costs. Date were analysed using SPSS (version 15.0).

The cost-minimisation form of economic analysis was adopted, ${ }^{17}$ as the RCT showed no significant differences in outcome. ${ }^{10}$ Analyses were performed according to the intention-to-treat principle. As cost data were highly skewed, estimates for costs were compared with estimates based on nonparametric clustered bootstrap (1000 replications) to check the robustness of the analysis. ${ }^{18,19}$ Both estimates gave similar results and so only the direct estimates are presented. Differences in clinical characteristics and healthcare use were analysed with Student's $t$ test (two-sided; $\alpha=0.05$ ) and $\chi^{2}$, where appropriate. Univariate linear regression and mixed model 
analysis were used to determine whether there were significant effects in scores between the intervention group and control group on the different scores after controlling for potential confounding variables.

\section{Sensitivity and subgroup analysis}

A sensitivity analysis was performed to test several assumptions in the cost analysis. The impact of salary was assessed by using two scenarios. The first scenario was the salary of 'GP in employment', working 38 hours weekly, and the second was based on the salary of a GP who is employed by GPs in partnership, working 40 hours weekly.

A subgroup analysis for patients $<65$ years of age was performed, since productivity costs were calculated for this group.

\section{RESULTS}

Considering the background characteristics, patients attending study practices and randomised to a GP were significantly older (mean age $=46.1$ years, $S D=$ 16.6 years) than those in the intervention group (mean age $=42.8$ years, $\mathrm{SD}=16.5$ years; $P<0.001$ ). No significant difference between groups in sex or complexity of diagnoses were identified.

There was no significant difference in sex between patients of the study practices and external reference practices (Table 2). Most patients were female (61.0\% versus $60.6 \%)$. Patients in external reference practices were on average more than 2 years older $(P$ $=0.001$ ) than those in study practices. Patients in study practices had, on average, more complex diagnoses than patients in external reference practices.

Within study practices there was no significant difference in resource use by patients treated by a nurse practitioner or a GP. Patients in the study practices had significantly fewer prescriptions
$(P<0.001)$ and diagnostic procedures $(P=0.04)$ than patients in the external reference practices (Table 3 ).

Results of the economic analyses are shown in Table 4. Within study practices, a significant difference in direct costs appeared between the nurse practitioner consultations and GP consultations: a mean difference was found in direct costs of $€ 8.21$ in favour of the nurse practitioner consultations $(P=0.001)$. No significant difference in direct costs and productivity costs was found between nurse practitioner consultations and GP consultations at study practices.

Between study practices and reference practices, a significant difference was found in the direct costs within health care (Table 5). The mean difference in direct costs was $€ 3.45$ per consultation in favour of the study practices $(P=0.04)$. Regarding the direct

Table 2. Patient characteristics.

\begin{tabular}{lccc} 
& $\begin{array}{c}\text { Study practices, } \\
n=1397\end{array}$ & $\begin{array}{c}\text { External reference } \\
\text { practices, } n=1350\end{array}$ & $P$-value \\
\hline Sex, \% male/female & $39.0 / 61.0$ & $39.4 / 60.6$ & 0.83 \\
\hline Age in years, mean (SD) & $45.1(16.7)$ & $47.2(18.2)$ & 0.001 \\
\hline $\begin{array}{l}\text { Complexity of the } \\
\text { diagnosis, \% low/high }\end{array}$ & $40.6 / 59.4$ & $47.0 / 53.0$ & 0.001 \\
\hline
\end{tabular}

Table 3. Resource use.

\begin{tabular}{lccc} 
& $\begin{array}{c}\text { Study practices, } \\
n=1397, \\
n(\%)\end{array}$ & $\begin{array}{c}\text { External reference } \\
\text { practices, } n=1350, \\
n(\%)\end{array}$ & \begin{tabular}{c}
$P$-value \\
\hline 1 prescription
\end{tabular} \\
\hline $263(54.6)$ & $889(65.9)$ & $<0.001$ \\
\hline$>3$ prescriptions & $253(18.1)$ & $307(22.7)$ & 0.003 \\
\hline piagnostiptions & $117(8.4)$ & $93(6.9)$ & 0.14 \\
\hline Referrals & $37(2.6)$ & $55(4.1)$ & 0.04 \\
\hline
\end{tabular}

Table 4. Cost analysis (in €) per nurse practitioner consultation and GP consultation at study practices.

\begin{tabular}{|c|c|c|c|c|c|}
\hline \multirow[b]{2}{*}{ All patients } & $\begin{array}{c}\text { Nurse practitioner } \\
\text { consultations }(I), \\
\text { mean }(\mathrm{SD}) \\
\end{array}$ & $\begin{array}{c}\text { GP } \\
\text { consultations }(R), \\
\text { mean }(\mathrm{SD}) \\
\end{array}$ & \multirow{2}{*}{$\begin{array}{c}\text { Mean difference, } \\
\Delta I-R(\%)\end{array}$} & \multirow[b]{2}{*}{$95 \% \mathrm{Cl}$} & \multirow[b]{2}{*}{$P$-value } \\
\hline & $n=747$ & $n=650$ & & & \\
\hline Direct costs ${ }^{a}$ & $31.94(36.29)$ & $40.15(49.94)$ & $-8.21(-20.45)$ & 3.56 to 12.85 & 0.001 \\
\hline Based on salary of GP in employment & $31.94(36.29)$ & 38.33 (49.94) & $-6.39(-16.67)$ & 1.74 to 11.03 & 0.007 \\
\hline Based on GP employed by other GPs & $31.94(36.29)$ & $37.45(49.94)$ & $-5.53(-14.76)$ & 0.88 to 10.16 & 0.02 \\
\hline Based on salary of GP in employment & $144.40(53.18)$ & $144.05(67.15)$ & $0.34(0.24)$ & -6.77 to 6.08 & 0.92 \\
\hline Based on GP employed by other GPs & $144.40(53.18)$ & $143.17(67.15)$ & $1.20(0.84)$ & -7.63 to 5.22 & 0.71 \\
\hline Patients $<65$ years & $n=666$ & $n=542$ & & & \\
\hline Direct costs and productivity costs & $161.57(33.98)$ & $170.75(46.58)$ & $-9.18(-5.38)$ & 4.48 to 13.88 & $<0.001$ \\
\hline Based on salary of GP in employment & $161.57(33.98)$ & $170.10(46.58)$ & $-8.52(-5.01)$ & 3.83 to 13.23 & $<0.001$ \\
\hline Based on GP employed by other GPs & $161.57(33.98)$ & $168.90(46.58)$ & $-7.33(-4.34)$ & 2.63 to 12.03 & 0.002 \\
\hline
\end{tabular}

aBased on resource use, costs of follow-up consultations, length of consultations, and salary costs. 
Table 5. Cost analysis (in €) per consultation in study practices and external reference practices.

\begin{tabular}{|c|c|c|c|c|c|}
\hline \multirow[b]{2}{*}{ All patients } & $\begin{array}{c}\text { Study practices }(I), \\
\text { mean }(\mathrm{SD})\end{array}$ & $\begin{array}{c}\text { External reference }(R), \\
\text { mean }(\mathrm{SD})\end{array}$ & \multirow{2}{*}{$\begin{array}{c}\text { Mean difference, } \\
\Delta l-\mathrm{R}(\%)\end{array}$} & \multirow[b]{2}{*}{$95 \% \mathrm{Cl}$} & \multirow[b]{2}{*}{$P$-value } \\
\hline & $n=1397$ & $n=1350$ & & & \\
\hline Direct costs ${ }^{a}$ & $35.76(43.35)$ & $39.21(42.99)$ & $-3.45(-8.80)$ & 0.22 to 6.68 & 0.04 \\
\hline Based on salary of GP in employment & $34.92(43.27)$ & 37.39 (42.99) & $-2.47(-6.60)$ & -0.75 to 5.70 & 0.13 \\
\hline Based on GP employed by other GPs & $34.50(43.24)$ & 36.51 (42.99) & $-2.01(-5.50)$ & -1.21 to 5.24 & 0.22 \\
\hline Direct costs and productivity costs & $145.08(60.07)$ & $141.09(63.03)$ & $4.00(2.83)$ & -8.61 to 0.61 & 0.09 \\
\hline Based on salary of GP in employment & $144.24(60.07)$ & $139.26(63.03)$ & $4.98(3.58)$ & -9.58 to 0.36 & 0.04 \\
\hline Based on GP employed by other GPs & $143.82(60.07)$ & $138.39(63.03)$ & $5.43(3.92)$ & -10.04 to 0.82 & 0.02 \\
\hline Patients $<65$ years & $n=1208$ & $n=1089$ & & & \\
\hline Direct costs and productivity costs & $165.69(40.37)$ & $168.25(40.48)$ & $-2.60(-1.55)$ & -0.74 to 5.88 & 0.13 \\
\hline Based on salary of GP in employment & $165.39(40.33)$ & $167.60(40.48)$ & $-2.21(-1.31)$ & -1.10 to 5.52 & 0.19 \\
\hline Based on GP employed by other GPs & $164.86(40.27)$ & $166.40(40.48)$ & $-1.55(-0.93)$ & -1.76 to 4.86 & 0.36 \\
\hline
\end{tabular}

${ }^{a} B a s e d$ on resource use, costs of follow-up consultations, length of consultations, and salary costs.

costs and productivity costs, the consultations in external reference practices cost less $(€ 141.09)$ than those in study practices ( $€ 145.08 ; P=0.09$ ), although this was not statistically significant.

Univariate linear regression revealed that direct costs were significantly associated with patients' sex $(F=4.13 ; P=0.042)$, age $(F=24.24 ; P=0.001)$, and type of diagnosis $(F=63.67 ; P<0.001)$. Direct costs were not significantly associated with the variable practice (meaning, patients nested within general practices). These variables explained $16.06 \%$ of the total variance (adjusted $R^{2}=0.40$ ).

\section{Sensitivity analysis}

Adjusting the salary of the GP (according to the salary of an employed GP, or of a GP employed by other GPs in partnership) affected the results to some degree. The significant difference in direct costs remained when comparing nurse practitioner consultations and GP consultations at study practices. Also, no significant difference was found regarding direct costs and productivity costs between consultations at study practices (Table 4). The impact of salary was found in the analyses between study practices and external reference practices; for direct costs and for direct costs and productivity costs, a significant difference between practices was not apparent (Table 5).

With patients in the reference groups being significantly older, a sensitivity analysis was performed for patients $<65$ years of age: within study practices the mean direct costs and productivity costs for nurse practitioner consultations were $€ 161.57$ (SD = 33.98) and for GP consultations $€ 170.75$ (SD = 46.58; $P<0.001$; Table 4). Furthermore, the mean costs for consultations in study practices were $€ 165.69$ (SD $=40.37$ ) and $€ 168.25$ for consultations in the external reference practices (SD $=40.48 ; P=0.13$; Table 5).

\section{DISCUSSION}

\section{Summary of main findings}

This study evaluated the costs of care provided by Dutch GPs or specially trained nurse practitioners as the first point of contact for patients with common conditions. From a general practice perspective, direct costs of nurse practitioner consultations were significantly less than those of GP consultations. The same results were found when comparing study practices with external references practices, showing direct costs of consultations in favour of study practices. Given that there were differences in the age of people both within the study practices as well as between study practices and external reference practices, the study looked at the impact of age on the direct costs plus productivity costs. This revealed that among those aged $<65$ years, direct costs plus productivity costs were significantly lower for nurse practitioner consultations than for GP consultations at study practices. Between study practices and external reference practices, no differences were found for direct costs plus productivity costs of consultations among those aged $<65$ years. Cost differences are mainly caused by the difference in salary between nurse practitioners and GPs. As the external reference practices also implemented triage, the difference in costs related to the allocation of patients between study practices and external reference practices is assumed to be marginal.

\section{Strengths and limitations of the study}

For pragmatic reasons, it was not possible to gather data for follow-up consultations, length of consultations, or number of days of absence in the external reference practices. As it was not possible to collect data on the follow-up after a referral, for each referral one initial consultation was calculated in order not to leave this type of event out of the 
calculation. Consultations were considered during the 2 weeks after the initial consultation. This study was not powered to determine the impact on adverse events (and related costs) or explore additional consultations.

The authors are aware of the preference for costeffectiveness analyses and cost-effectiveness planes as a valuable tool in the interpretation of both costs and effects. ${ }^{17,20}$ The use of cost-minimisation analysis is, in most cases, regarded as inappropriate in studies designed to compare the cost-effectiveness of two interventions. ${ }^{20,21}$ However, in comparing nurse practitioner or GP consultations, no significant differences in outcome or process measures were found..$^{10}$ Consequently, it was considered that the sum of these measures represents equivalence between the intervention group and reference group within the study practices. As a result, no cost-effectiveness analysis was conducted. If it had been, it is very unlikely this would have altered the study findings on costs, given the equivalence in effectiveness.

\section{Comparison with existing literature}

Earlier reviews, mainly based on British studies, 5,6 found no significant differences in costs between nurse practitioner consultations and GP consultations. Hollinghurst et al included training costs and advice time in their analyses..$^{22}$ Other factors that could explain differences between studies are the types of diagnoses being addressed (for example, chronic disease versus common conditions), specific competencies or consulting styles (for example, no prescriptive authority), and work experience, as well as differences in training programmes followed by providers. The training of nurses and GPs is funded through a variety of mechanisms, which may not accurately reflect the true costs, ${ }^{22}$ and makes an international comparison unclear.

\section{Implications for future research and clinical practice}

Most decisions taken by health policy makers will not be about whether services should be delegated or substituted, but about the degree to which existing services should change. ${ }^{23}$ This study found a cost difference of $€ 2.01$ per consultation, based on a mix of GP consultations and nurse practitioner consultations and the salary of a GP who is employed by GPs in partnership. To illustrate the impact of such a difference at a national level, a scenario was calculated wherein all consultations of common conditions would be performed by nurse practitioners instead of GPs.

Taking account of one full-time equivalent nurse practitioner employed per four GPs, 8400 employed
$\mathrm{GPs}^{24}$ and 20 nurse practitioner consultations per day, ${ }^{25}$ a cost reduction of $€ 19$ million per year could be realised. This amount should not be considered as a pure economic saving. When involving the nurse practitioner in the care of patients with common conditions, this substantial amount should be used partly for redesigning primary care. ${ }^{9}$ As a result, GPs should have longer consultations for an increasing number of patients with complex diagnoses or multi morbidity, more time for coordination between professionals, and more time for their supervisory role to other professionals.

When common conditions are extracted from the repertoire of GP consultations, the GP role of coordinator and supervisor will be very important for management of less complex care. Such redesign requires the healthcare system to take a long-term perspective, which may be difficult to achieve in practice. ${ }^{8}$ It is important to continue the debate between policymakers and researchers about the meaning of results from economic evaluations, ${ }^{26,27}$ to optimise the best skill mix (that is, effective and efficient), and to cover the full range of primary care activities.

As the regression analysis resulted in a model explaining only a marginal amount of the variance in results, more research is needed. Qualitative research should be performed to explore factors that influence costs, followed by quantitative research to retest the model. Finally, it is recommended that more research is carried out to study the costeffectiveness of innovations in health care over a long-term period, beyond the time horizon of a trial.

\section{Funding body}

Dutch Ministry of Health, Welfare and Sport and the Health Insurers CZ and VG, Foundation ROS Robuust, The Province of North-Braban, the Netherlands

\section{Ethics committee}

Informed consent was obtained and ethical approval for the study obtained from the local medical ethical judgment committee, Eindhoven, the Netherlands

\section{Competing interests}

The authors have stated that there are none

\section{Acknowledgements}

The authors would like to thank the patients, practice assistants, nurse practitioners, and GPs for their invaluable contribution to this paper. Thanks are also extended to the associates of Meetpunt Kwaliteit, who had an important role in data extraction from the computer systems, and Joyce Janssen for her conscientious assistance during the whole study period.

\section{Discuss this article}

Contribute and read comments about this article on the Discussion Forum: http://www.rcgp.org.uk/bjgp-discuss

\section{REFERENCES}

1. Lancaster J, Lancaster W, Onega LL. New directions in health-care reform: the role of nurse practitioners. J Business Res 2000; 48(3): 207-212.

2. Vrijhoef HJM, Diederiks JP, Spreeuwenberg C. Effects on quality of care for patients with NIDDM or COPD when the specialised nurse has a central role: a literature review. Patient Educ Couns 
2000; 41(3): 243-250.

3. Buchan J, Dal Poz MR. Skill mix in the health care workforce: reviewing the evidence. Bull World Health Organ 2002; 80(7): $575-580$

4. Horrocks S, Anderson E, Salisbury C. Systematic review of whether nurse practitioners working in primary care can provide equivalent care to doctors. BMJ 2002; 324(7341): 819-823.

5. Laurant M, Reeves D, Hermens R, et al. E. Substitution of doctors by nurses in primary care. Cochrane Database Syst Rev 2004; (4): CD001271.

6. Dierick-van Daele ATM, Spreeuwenberg C, Derckx EWCC, et al. Critical appraisal of the literature on economic evaluations of substitution of skills between professionals: a systematic literature review. J Eval Clin Prac 2008; 14(4): 481-492.

7. Richardson G, Maynard A. Fewer doctors? More nurses? A review of the knowledge base of doctor-nurse substitution. Discussion paper 135. York: University of York, 1995

8. Williams A, Sibbald B. Changing roles and identities in primary health care: exploring a culture of uncertainty. J Adv Nurs 1999; 29(3): 737-745.

9. Sibbald B. Should primary care be nurse led? BMJ 2008; 337: a1157. doi: 10.1136/bmj.39661.707083.59

10. Dierick-van Daele ATM, Metsemakers JFM, et al. Nurse practitioners substituting for general practitioners in the care for patients with common complaints; a randomised controlled trial. J Adv Nurs 2009; 65(2): 391-401.

11. Lamberts H, Wood M. ICPC. International classification of primary care. Oxford: Oxford University Press, 1987.

12. Gebel RS, Lamberts H. NHG-ICPC-1 [Dutch College of General Practitioners - ICPC1]. 4th edn. Utrecht: Dutch College of General Practitioners, 2000.

13. Van der Linden MW, Westert GP, de Bakker DH, Schellevis FG. Tweede nationale studie naar ziekten en verrichtingen in de huisartspraktijk. Klachten en aandoeningen in de bevolking en in de huisartspraktijk. [Second national study of diseases and treatments in general practices. Complaints and illnesses in the Dutch population and in general practice]. Utrecht/Bilthoven: Dutch Insitute for Health Services Research (NIVEL)/National Institute for Public Health and Environment (RIVM), 2004.

14. Oostenbrink JB, Koopmanschap MA, Rutten FF. Handleiding voor kostenonderzoek, methoden en richtlijnprijzen voor economische evaluaties in de gezondheidszorg. [Handbook for cost studies, methods and guidelines for economic evaluation in health care.] Hague: Health care Insurance Council, 2004.
15. Pharmotherapeutic Compass. Health Care Insurance Board (CVZ) http://www.fk.cvz.nl/ (accessed 27 Sept 2009).

16. Central Bureau of Statistics. Price index rates. http://www.cbs.nl/Statline (accessed 27 Sept 2009).

17. Drummond, MF, O’Brien, B, Stoddart GL, Torrance GW. Method for the economic evaluation of health care programmes. 2nd edn. Oxford: Oxford University Press, 2003.

18. Barber JA, Thompson SG. Analysis and interpretation of cost data in randomised controlled trials: review of published studies. BMJ 1998; 317(7167): 1195-1200

19. Thompson SG, Barber JA. How should cost data in pragmatic randomized trials be analyzed. BMJ 2000; 320(7243): 1197-1200.

20. Bosmans, JE, de Bruijne MC, van Hout HP, et al. Practical guidelines for economic evaluations alongside equivalence trials. Value Health 2008; 11(2): 251-258.

21. Briggs AH, O'Brien BJ. The death of cost minimization analysis? Health Econ 2001; 10(2): 179-184.

22. Hollinghurst S, Horrocks S, Anderson E, Salisbury C. Comparing the cost of nurse practitioners and GPs in primary care; modelling economic data from randomised trials. Br J Gen Pract 2006; 56(528): 530-535.

23. Kernick DP. Developing intermediate care provided by general practitioners with a special interest: the economic perspective. $\mathrm{Br} J$ Gen Pract 2003; 53(492): 553-556.

24. Landelijke Huisartsen Vereniging. The national association of general practice. Capacity rates in general practices [In Dutch]. http://lhv.artsennet.nl/huisartsenzorg/Cijfers-1.htm (accessed 18 Nov 2009).

25. Dierick-van Daele ATM, Spreeuwenberg C, Derckx EWCC, et al. De Nurse practitioner in de huisartsenpraktijk, het onderzoeksrappor [The nurse practitioner in general practice, the research report] Maastricht: Maastricht University Medical Center, 2008.

26. Eddamaa O, Coast J. A systematic review of the use of economic evaluation in local decision-making. Health Policy 2008; 86(2-3): 129-141.

27. Graf von der Schulenburg JM. The influence of economic evaluation studies on health care decision making. A European survey. Amsterdam: IOS Press, 2000.

28. Reay T, Golden-Biddle K, Germann K. Challenges and leadership strategies for managers of nurse practitioners. J Nurs Manag 2003; 11(6):396-403. 


\section{Appendix 1. Summary of randomised controlled trial. ${ }^{10}$}

The aim of the study was to evaluate process and outcomes of care provided by GPs or specially trained nurse practitioners for patients with minor conditions at first point of contact.

A total of 1501 patients were randomised for an initial consultation by a GP or a nurse practitioner, working in 15 general practices. Data were collected by means of questionnaires, extracting medical records from the practice computer systems, and recording the length of consultations.

In both groups, patients greatly appreciated the quality of care. No statistically significant differences were found in patient satisfaction, the provision of information, communication and attitude, health status (including burden of illness and concerns regarding the illness), compliance of practical guidelines, or medical consumption: prescriptions (nurse practitioner $55.0 \%$, GP $54.2 \% ; P=0.75$ ), investigations ordered (nurse practitioner $2.4 \%$, GP $2.9 \% ; P=0.55$ ) and referrals (nurse practitioner $12.0 \%, \mathrm{GP} 14.2 \% ; P=0.24$ ).

Patients in the intervention group were more often invited to re-attend (nurse practitioner $50.3 \%, \mathrm{GP} 41.3 \% ; P=0.001$ ), had more follow-up consultations (nurse practitioner $23.5 \%$, GP $18.3 \% ; P=0.04$ ), and their consultations took significantly more time (nurse practitioner mean 12.22 minutes [SD = 5.7], GP mean $9.20[\mathrm{SD}=4.8] ; P=0.001$ ).

It was concluded that nurse practitioners and GPs provide comparable care. These findings support an increased involvement of specially trained nurse practitioners in Dutch primary care, and contribute to the knowledge on the effectiveness of care provision by nurse practitioners from a national and international perspective. 